\title{
Job embeddedness, work engagement and turnover intention of staff in a higher education institution: An exploratory study
}

\author{
Authors: \\ Ndayiziveyi Takawira ${ }^{1}$ \\ Melinde Coetzee ${ }^{2}$ \\ Dries Schreuder ${ }^{2}$ \\ Affiliations: \\ ${ }^{1}$ Department of Human \\ Resource Management, \\ University of South Africa, \\ South Africa \\ ${ }^{2}$ Department of Industrial \\ and Organisational \\ Psychology, University of \\ South Africa, South Africa \\ Correspondence to: \\ Ndayiziveyi Takawira \\ Email: \\ takawn@unisa.ac.za \\ Postal address: \\ PO Box 392, Pretoria 0003, \\ South Africa \\ Dates: \\ Received: 30 Jan. 2013 \\ Accepted: 25 Feb. 2014 \\ Published: 06 May 2014 \\ How to cite this article: \\ Takawira, N., Coetzee, M., \\ \& Schreuder, D. (2014). \\ Job embeddedness, work \\ engagement and turnover \\ intention of staff in a higher \\ education institution: \\ An exploratory study. SA \\ Journal of Human Resource \\ Management/SA Tydskrif vir \\ Menslikehulpbronbestuur, \\ 12(1) Art. \#524, 10 pages. \\ http://dx.doi.org/10.4102/ \\ sajhrm.v12i1.524

\section{Copyright:} \\ (C) 2014. The Authors. \\ Licensee: AOSIS \\ OpenJournals. This work \\ is licensed under the \\ Creative Commons \\ Attribution License. \\ Read online: \\ Scan this $Q R$ \\ code with your \\ smart phone or \\ mobile device \\ to read online.
}

Orientation: The world economy is becoming increasingly knowledge driven, and intellectual capital is now considered as a human resource that affords organisations a competitive advantage. A high turnover rate in higher education and the importance of retaining staff are concerns that have resulted in increased interest in psychological variables, such as job embeddedness and work engagement that may influence employee retention.

Research purpose: The objective of this study was to explore the relationship between job embeddedness, work engagement and turnover intention of staff in a higher education institution.

Motivation for the study: Research on how employees' job embeddedness and work engagement influence their turnover intention is important in the light of organisational concerns about retaining knowledgeable staff in the current higher education environment.

Research design, approach and method: A cross-sectional quantitative survey was conducted on a non-probability purposive sample $(N=153)$ of academic and non-academic staff in a South African higher education institution.

Main findings: Correlational analyses revealed significant relationships between job embeddedness, work engagement and turnover intention. Multiple regression analyses showed that organisational links and dedication significantly and negatively predict turnover intention.

Practical/managerial implications: When designing retention strategies, management and human resource practitioners need to recognise how job embeddedness and work engagement influence the turnover intention of higher education staff.

Contribution: These findings contribute valuable new knowledge that can be applied in the retention of staff in the higher education environment.

\section{Introduction}

\section{Key focus of the study}

As the global economy is increasingly knowledge driven, and with a global skills shortage, intellectual capital has become a source of competitive advantage for organisations (Halawi, Aronson \& McCarthy, 2005; Powell \& Snellman, 2004). Furthermore, more organisations are awakening to the need to grow the intellectual capital of their employees in order to compete successfully in an increasingly demanding global economy (Burke \& El-Kot, 2010; Lawler, 2008). Retention of talent has, therefore, become more critical, both in South Africa and globally. (Macey \& Schneider, 2008; Powell \& Snellman, 2004; Ryder, 2010).

The present study seeks to contribute to the literature on staff retention by focusing on the relationship between the constructs of job embeddedness and work engagement, and the turnover intention of employees. These variables have been linked to staff retention in the research literature (Halbesleben \& Wheeler, 2008) but their relationship has not been examined in the South African higher education context. This investigation seeks to contribute to the retention of staff in the higher education environment in South Africa by making recommendations for developing job embeddedness and work engagement, based on the findings of the study.

\section{Potential value-add}

This article contributes valuable new knowledge that could be used to inform retention strategies for employees in the higher education environment and may stimulate further research to promote a better understanding of the role of the three constructs described in retaining staff. 


\section{Background to the study}

Higher education plays a critical role in the creation of knowledge for the cultivation of future talent and socioeconomic development in South Africa (Van den Berg, Manias \& Burger, 2008). Socio-economic and political strategies implemented by governments competing in the global economy are increasingly impacting negatively on the availability of talent in higher education (Makhanya, 2012). Furthermore, new labour market demographics, globalisation and competitive pressures have become essential for businesses to be effective (Marchington \& Wilkinson, 2008). Academics are essential to societal life, because they are responsible for educating the leaders of society, as well as for conducting scientific research and furthering knowledge (Coetzee \& Rothmann, 2004). However, higher education institutions in South Africa have become vulnerable to losing their highly qualified knowledge workers to wellpaid offers from the private sector, and headhunting from other higher education institutions internationally (Ngobeni \& Bezuidenhout, 2011). Martin and Roodt (2008) note in this regard the need for further studies to establish the turnover behaviour of academic staff in higher education institutions.

Institutional knowledge is a key component in the knowledge economy, (Powell \& Snellman, 2004); managing knowledge through knowledge identification, acquisition, development, transfer and retention is, therefore, particularly important in higher education institutions (Probst, Raub \& Romhardt, 2000). Moreover, these institutions not only produce highly skilled and enlightened intellectual capital for the social transformation and economic development of a nation (Shikha, 2012), but their core business activities, including research and development, require talented human capital to deliver quality learning experiences to students (Netswera, Rankumise \& Mavundla, 2006).

Recognising the forces that keep employees in their current employment is critical in attracting and retaining talented staff in higher education institutions (Lawler \& Finegold, 2000; Michaels, Handfield-Jones \& Axelrod, 2001). Retention of talented staff promotes better decision-making capabilities, enhanced quality of curriculum programmes based on best practices, improved academic services and reduces turnover costs (Kidwell, Vander Linde \& Johnson, 2000). Consequently, higher education institutions can succeed in contributing to the socio-economic development of South Africa by retaining the critical human capital that makes it possible to provide higher education to all stakeholders, including students and society as a whole (Coetzee \& Rothman, 2004; Van den Berg, Bakker \& Ten Cate, 2013).

Turnover has significant implications for an organisation, with influencing factors such as the potential cost of human capital loss and interruption of ongoing organisational activities (Smyth, Zhai \& Li, 2009). Research indicates that job embeddedness and work engagement have emerged in the current world of work as constructs that may significantly influence employees' turnover intention (Halbesleben \&
Wheeler, 2008; Mitchell, Holtom \& Lee, 2001a). In particular, employees with low levels of job embeddedness and work engagement are more likely to have a higher intention of leaving the organisation, as well as actually leaving it (Mitchell, Holtom, Lee, Sablynski \& Erez, 2001b).

Talent retention is becoming more essential as an organisation's human capital increasingly becomes the key source of competitive advantage (Halawi et al., 2005; Pfeffer, 2005). A growing awareness of shifts in the characteristics of the workforce is calling for organisations to be more focused in retaining skilled employees, keeping them fully engaged and embedding them in their jobs (Frank, Finnegan \& Taylor, 2004). It is therefore vital for organisations to be able to make informed decisions about developing effective retention practices that result in the reduction of turnover. (Hillmer, Hillmer \& McRoberts, 2004).

\section{Research objective}

The objective of the present study is to explore the relationship between the job embeddedness, work engagement and turnover intention of staff in a higher education institution. In the light of the need to retain talented staff in the South African higher education context (Martin \& Roodt, 2008; Ngobeni \& Bezuidenhout, 2011), it may prove valuable to explore the relationship between these variables. Employees' job embeddedness and work engagement are starting to be recognised as important factors in retaining valuable talented employees and are seen to offer organisations a competitive advantage (Bakker, Schaufeli, Leiter \& Taris, 2008; Du Plooy \& Roodt, 2010; Mitchell et al., 2001a). This recognition suggests the value of an investigation of these variables in the higher education context. Should significant associations be detected between these variables in this exploratory study, more expanded studies can be conducted in the higher education environment. The results of these follow-up studies can then also be compared with studies of staff in other occupational contexts.

\section{Literature review \\ Job embeddedness}

Job embeddedness is defined as '... the combined forces that keep a person from leaving his or her job' (Yao, Lee, Mitchell, Burton \& Sablynski, 2004, p. 159). Although job embeddedness consists of two dimensions, organisational and community embeddedness (Mitchell et al., 2001b) researchers have found that when job relocation is not a factor, organisational dimensions better predict employee retention than do community dimensions (Allen, 2006; Lee, Mitchell, Sablynski, Burton \& Holtom, 2004). Thus, in this study, the investigation of job embeddedness is restricted to the organisational dimensions. Mitchell et al. (2001b) conceptualise job embeddedness as connections to other aspects of the job (e.g. people and groups), the perception of a person-job fit and the sacrifices related to leaving the job. Job embeddedness is a relatively new construct that was developed by Mitchell et al. (2001b) and represents a broad 
collection of factors that influence an employee's decision to remain in or to leave an organisation.

According to Mitchell and Lee (2001), the critical characteristics of job embeddedness have to do with links that individuals have on the job, their fit with their jobs and what they would have to give up or sacrifice should they consider leaving their jobs. Mitchell et al. (2001b) suggest that the link aspects of embeddedness are formal or informal connections between an employee and other entities on the job. As the number of these links increases, the greater the likelihood becomes that an employee will stay in the organisation (Holtom, Mitchell \& Lee, 2006). 'Fit' refers to an employee's perceived compatibility with the organisation as well as with his or her job; hence, a higher fit shows higher embeddedness (Holtom et al., 2006). Finally, 'sacrifice' has to do with perceived costs of benefits, whether material or psychological, that may be lost by leaving the job. Thus, the higher the perceived cost, the greater the embeddedness will be (Halbesleben \& Wheeler, 2008; Holtom et al., 2006).

Many people stay in organisations as a result of connections they have to people (e.g. co-workers or network groups), projects they are involved in or sponsored community engagement activities (Mitchell et al., 2001a). Friedman and Holtom (2002) suggest that the more connected a person is professionally and socially, the more likely he or she is to stay in their organisation. Therefore, leaving a job often requires individuals to sacrifice or give up perks, routines or social networks in projects with which they have grown familiar (Mitchell et al., 2001a). Several studies have found that individuals embedded in their jobs are less likely to leave than those who are not embedded in their jobs (Allen, 2006; Mitchell et al., 2001b)

Mitchell et al. (2001a) suggest that analysing job embeddedness differs from traditional models for predicting turnover because it focuses on employee retention rather than employee turnover. This view is supported by Mitchell and Lee (2001) who found that job embeddedness predicted turnover better than the traditional job attitude models. Therefore, the theory of job embeddedness focuses on keeping employees in the organisation, rather than keeping them from leaving for other organisations (Mitchell et al., 2001a).

Research has found a significant negative relationship between job embeddedness and turnover intention (Allen, 2006; Crossley, Bennet, Jex \& Burnfield, 2007; Halbesleben \& Wheeler, 2008). In addition, job embeddedness seems to predict turnover more than combinations of perceived desirability and ease of movement measures do (e.g. job satisfaction, organisational commitment, job alternatives and job search). Mitchell and Lee (2001) highlight the fact that highly embedded and satisfied employees are less likely to search for alternative employment opportunities. On the other hand embedded employees may feel stuck in unfavourable jobs, experience frustration or lose motivation due to fear of losing connections with entities of the job, or what they would have to give up should they consider leaving their jobs (Crossley et al., 2007). In the context of the present study, the focus is on the positive aspects of job embeddedness, that is, the forces that keep people satisfied with and engaged in their jobs.

\section{Work engagement}

Work engagement is a theoretical concept that has emerged in the field of psychology (Bakker et al., 2008) and research in work engagement has been a focus of interest for the past ten years, culminating in two different schools of thought that distinguish burnout from work engagement (Maslach, Schaufeli \& Leiter, 2001; Schaufeli, Salanova, GonzalezRoma \& Bakker, 2002). For the purposes of this study, work engagement entails 'a positive, fulfilling, work-related state of mind that is characterised by vigour, dedication, and absorption' (Schaufeli et al., 2002, p.74). According to Schaufeli et al. (2002), work engagement is a constant and affective cognitive state that does not focus on an object, occasion or the behaviour of an individual. As indicated in the definition, engagement has three primary components. The first is vigour, which relates to elevated levels of energy and mental resilience when occupied with a work activity, the willingness to invest effort in one's work activity and showing perseverance when faced with difficulty. Thus, employees who feel great vigour at work are highly motivated by their jobs and are likely to remain persistent when encountering difficulties (Mauno, Kinnunen \& Ruokolainen, 2006). The second component, dedication, is characterised by a strong involvement and pride in one's work, coupled with a sense of significance, passion, and inspiration. The final dimension of work engagement is absorption, which is characterised as being so completely focused and absorbed in one's work that time passes rapidly and one has difficulty detaching from a work activity (Schaufeli et al., 2002).

Saks (2006) suggests that work engagement is associated with an individual's attitudes, intentions and behaviours. Therefore, engaged employees are likely to be more attached to their organisation and would have a lower propensity to leave it (Schaufeli \& Bakker, 2004). This view is supported by several researchers who found that work engagement is negatively related to turnover intention (Du Plooy \& Roodt, 2010; Harter, Schmidt \& Hayes, 2002). Work engagement was found to have positive results relating to job satisfaction, a motivated workforce, employee well-being and less likelihood of leaving an organisation (Barkhuizen \& Rothmann, 2006; Schaufeli \& Bakker, 2004; Van den Berg, Bakker \& Ten Cate, 2013; Yeh, 2013). In addition, a metaanalysis of 7939 business units in 36 companies by Harter et al. (2002) reported a significant positive relationship between work engagement and business outcomes such as customer satisfaction and loyalty, profitability, turnover and safety.

Bakker and Demerouti (2008) proposed four reasons why engaged employees perform better than unengaged employees. Firstly, engaged employees were found to have 
positive sentiments towards their job, consequently leading to productivity. Secondly, engaged employees were seen to be more open to work opportunities and more confident and optimistic (Cropanzano \& Wright, 2001). Thirdly, research suggests that engagement is positively related to employee well-being, leading to better performance (Bakker \& Demerouti, 2008; Schaufeli \& Bakker, 2004; Shimazu, Schaufeli, Kubota \& Kawakami, 2012). Lastly, engaged employees work more productively because they have the ability to create their own resources. Xanthopoulou, Bakker, Demerouti, and Schaufeli (2007) found in their study of highly skilled Dutch technicians that personal resources (optimism, self-efficacy and organisational-based self-esteem) resulted in higher levels of work engagement.

\section{Turnover intention}

Turnover intention is defined as the manifestation of 'the (subjective) probability that an individual will change his or her job within a certain time period' (Sousa-Poza \& Henneberger, 2002, p.1), whereas turnover is a voluntary occurrence or event which is defined as the individual movement across the membership boundary of an organisation' (Price, 2001, p. 600). Contrary to turnover, turnover intentions are not definite, but are often associated with job search behaviour (Sousa-Poza \& Henneberger, 2002). According to Karatepe and Ngeche (2012), employees with turnover intentions tend to render poor service and corrode organisational effectiveness. Research has shown that intent to leave an organisation is one of the indicators of turnover (Bothma \& Roodt, 2013). From the organisation's perspective, turnover of employees can lead to costs arising from recruitment, selection, training or the employment of temporary staff (Morrell, Loan-Clarke \& Wilkinson, 2004). In addition, turnover may have an effect on the organisational culture or employee morale (Morrell et al., 2004).

Coetzee and Schreuder (2010) suggest that external factors, such as competition for talent and the availability of alternative jobs in the local or global economy, contribute to the problems of high employee turnover. However, embeddedness and engagement have become popular concepts that promote employee retention (Halbesleben \& Wheeler, 2008). As an employee retention theory, job embeddedness is a combination of forces that keep an individual from leaving the job (Mitchell et al., 2001b) whereas work engagement represents a positive work-focused psychological state that keeps an employee in the job (Schaufeli et al., 2002).

\section{The relationship between job embeddedness, work engagement and turnover intention}

According to Halbesleben and Wheeler (2008), job embeddedness represents a build-up of connections (e.g., coworkers or networks) that will be difficult to replace outside the organisation. Likewise, a move out of the organisation may require an excellent alternative to be worth the sacrifice of invested resources. Job embeddedness is related to the organisation and the workplace, thus higher levels of job embeddedness would be related to lower intention to leave the organisation. Work engagement, on the other hand, is more related to energy and psychological attachment to one's job; thus, employees who are more engaged with their work may be unwilling to disengage owing to the invested energy and high levels of identification with the job (Bakker et al., 2008).

Mitchell et al. (2001b) and Schaufeli and Bakker (2004) suggest that turnover intention can be driven by a lack of embeddedness and a disengaged workforce. Limited information is available on the relationship between job embeddedness, work engagement and turnover intention. However, a study by Halbesleben and Wheeler (2008) reported a significant relationship between these three constructs. In terms of job embeddedness and turnover intention, Mitchell et al. (2001b) reported that people who are embedded in their jobs have less intent to leave the organisation, whilst Halbesleben (2010) found a significant relationship between work engagement and turnover intention.

Considering that both job embeddedness and work engagement are regarded as key constructs that drive employees' turnover decisions (Halbesleben \& Wheeler, 2008), the following hypotheses were formulated.

H1 : A statistically significant relationship exists between individuals' job embeddedness, work engagement and turnover intention.

H2: Job embeddedness and work engagement negatively predict turnover intention.

\section{Method \\ Research approach}

The study utilised a cross-sectional survey design to collect quantitative primary data by using self-administered questionnaires (Leedy \& Ormrod, 2005).

\section{Research design \\ Research participants}

A non-probability purposive sample of 153 employees of a South African higher education institution participated in the study. The group comprised professors, senior lecturers, lecturers and support professionals in the institution's College of Economic and Management Sciences.

The racial composition of the sample was predominately African (52\%), with the rest of the sample comprising white $(37 \%)$, Asian (8\%) and mixed race (3\%) people. Participants were in the early and mid-career stage (26-45 years) and most (54\%) had been in the organisation's employment for at least five years and (59\%) had been in their current position for at least five years. Overall, married (66\%) and female (61\%) participants dominated the sample.

\section{Measuring instruments}

The Job Embeddedness Scale (JES): The JES (Mitchell et al., 2001b) is a self-report instrument that includes three scales, 
namely links (e.g., 'My co-workers are similar to me'), fit (e.g., 'My job utilises my skills and talents well'), and sacrifice (e.g., 'I would sacrifice a lot if I left this job'). The response scale was scored on a six-point Likert scale varying between degrees of intensity, for example, from 1 'strongly disagree' to 6 'strongly agree'. A higher response aggregate indicates higher levels of job embeddedness.

Mitchell et al. (2001b) reported acceptable internal consistency reliabilities (Cronbach's alpha) for links (6 items) $\alpha=0.68$, fit (7 items) $\alpha=0.87$ and sacrifice ( 10 items) $\alpha=0.86$. Various studies have reported the validity of the JES (Burton, Holtom, Sablynski, Mitchell \& Lee, 2010; Halbesleben \& Wheeler, 2008; Mitchell et al., 2001b). Acceptable internal consistency reliability links $(\alpha=0.79)$, fit $(\alpha=0.81)$ and sacrifice $(\alpha=0.88)$ were yielded in the present study.

The Utrecht Work Engagement Scale (UWES): The UWES (Schaufeli \& Bakker, 2003) measures three integral aspects of work engagement. The UWES is a self-report instrument that includes three scales, namely vigour (e.g.,'I am bursting with energy in my work'), dedication (e.g., 'I find the work that I do full of meaning and purpose'), and absorption (e.g., 'Time flies when I am working'). The response scale was scored on a seven-point Likert scale varying between poles of intensity, for example, from 0 'never' to 6 'always'. Barkhuizen and Rothmann (2006) and Schaufeli and Bakker (2004) reported acceptable Cronbach alpha internal consistency reliability coefficients for the three subscales between 0.68 and 0.91 . A South African study by Storm and Rothmann (2003) reported the following alpha coefficients for the three subscales: vigour (6 items) $\alpha=0.78$, dedication ( 5 items) $\alpha=0.89$ and absorption (6 items) $\alpha=0.78$. The UWES has been validated in several countries, including South Africa (Albrecht, 2013; Schaufeli \& Bakker, 2003; Schaufeli et al., 2002; Storm \& Rothmann, 2003). Acceptable internal consistency reliabilities were yielded for the three subscales: vigour $\alpha=0.85$, dedication $\alpha=0.88$ and absorption $\alpha=0.87$ in the present study.

The Turnover Intention Scale (TIS): The TIS (Mitchell et al., 2001b), was used to measure employee intentions of leaving an organisation. The TIS is a self-report instrument that includes only three items. The response scale was scored on a six-point Likert scale varying between poles of intensity, for example, from 1 'strongly disagree' to 6 'strongly agree'. An example of a statement from the TIS is 'I intend to leave the organisation in the next 12 months'. Internal consistency reliability coefficient was reported as between 0.88 and 0.91 (Al-Sharafi \& Rajiani, 2013; Halbesleben \& Wheeler, 2008; Mitchell et al., 2001b). An acceptable internal consistency reliability of $\alpha=0.97$ was yielded in this study.

\section{Research procedure}

Ethical approval for the study was obtained from the higher education institution before the measuring instruments were distributed. Distribution was done using the contact information list of academics and support professionals working in the College of Economics and Management
Sciences, which is available for use by employees in the institution. A purposively chosen group was requested to participate in the research by completing the JES, UWES and TIS questionnaires. The participants were approached directly and provided with a covering letter explaining the purpose of the study. Informed consent was obtained and it was emphasised that participation in the study was voluntary, anonymous and confidential. The participants were asked to return the completed questionnaire to the address provided. A sample of 153 usable questionnaires was returned.

\section{Statistical analyses}

The statistical analysis was conducted using the SPSS software, version 20.0.0 (SPSS, 2011). Descriptive, correlational and inferential statistics were used to analyse the data. The Cronbach alpha coefficient was used to assess the internal consistency reliability of each of the measuring instruments. Pearson's product-moment correlations were performed to test the research hypothesis $\mathrm{H} 1_{\mathrm{a}}$. In order to counter the probability of a type 1 error, it was decided to set the significance value at a $95 \%$ confidence interval level $(p \leq 0.05)$. For the purposes of this study, $r$ values larger than 0.30 (medium effect) (Cohen, 1992) were regarded as practically significant.

The relationship between the three variables was further analysed by performing multiple regression analyses to explore the proportion of variance in the dependent variable (turnover intention) that is explained by the independent variables (job embeddedness and work engagement) (Tredoux \& Durrheim, 2013). The value of the adjusted $R^{2}$ $(\mathrm{F} p \leq 0.05)$ was used to interpret the results and $R^{2}$ values larger than 0.13 (medium effect) (Cohen, 1992) were regarded as practically significant.

\section{Results}

\section{Descriptive statistics}

Table 1 provides the means, standard deviations, skewness, kurtosis and internal consistency reliability coefficients for the job embeddedness, work engagement and turnover intention variables. The results show that the reliability of the factors, as measured by Cronbach's alpha, are all above 0.70 , which confirms the internal consistency of the items in a variable. In terms of the JES means and standard deviations, Table 1 shows that the total JES mean average score was $(\mathrm{M}=4.50 ; \mathrm{SD}=0.78)$. Fit to the organisation obtained the highest mean score $(\mathrm{M}=4.79 ; \mathrm{SD}=0.78)$, followed by sacrifice to the organisation $(\mathrm{M}=4.28$; $\mathrm{SD}=0.92)$. The lowest mean score was obtained on the links to the organisation subscale $(\mathrm{M}=4.27$; $\mathrm{SD}=0.93)$. The skewness and kurtosis values for the JES ranged between -0.02 and 0.49 , excluding the fit to organisation skewness (-1.12) and kurtosis (1.47), thereby not falling within -1 and +1 normality range recommended for these coefficients (Howell, 2008).

In terms of the UWES means and standard deviations, Table 1 shows that the total UWES mean average score was 
TABLE 1: Descriptive statistics: Job Embeddedness Scale, Utrecht Work Engagement Scale and Turnover Intention Scale.

\begin{tabular}{|c|c|c|c|c|c|}
\hline Measuring instrument subscales & Mean & SD & Skewness & Kurtosis & Cronbach's alpha coefficient \\
\hline JES & 4.50 & 0.78 & -0.91 & 0.49 & 0.90 \\
\hline Links & 4.27 & 0.93 & -0.58 & -0.45 & 0.79 \\
\hline Fit & 4.79 & 0.78 & -1.12 & 1.47 & 0.81 \\
\hline Sacrifice & 4.28 & 0.92 & -0.70 & -0.02 & 0.88 \\
\hline UWES & 4.37 & 0.90 & -0.51 & 0.04 & 0.95 \\
\hline Vigour & 4.36 & 0.88 & -0.33 & -0.28 & 0.85 \\
\hline Dedication & 4.50 & 0.97 & -0.62 & 0.12 & 0.88 \\
\hline Absorption & 4.30 & 0.98 & -0.51 & 0.25 & 0.87 \\
\hline TIS & 1.98 & 1.44 & 1.44 & 1.04 & 0.95 \\
\hline
\end{tabular}

Note: $n=153$

SD, significant difference; JES, Job Embeddedness Scale; UWES, Utrecht Work Engagement Scale; TIS, Turnover Intention Scale.

$(\mathrm{M}=4.37 ; \mathrm{SD}=0.90)$. The dedication subscale obtained the highest mean score $(\mathrm{M}=4.50 ; \mathrm{SD}=0.97)$ followed by vigour $(\mathrm{M}=4.36 ; \mathrm{SD}=0.88)$. The lowest mean score was obtained on the absorption subscale $(\mathrm{M}=4.30 ; \mathrm{SD}=0.98)$. The skewness and kurtosis values for the UWES ranged between -0.33 and 0.25 , thereby falling within the -1 and +1 normality range recommended for these coefficients (Howell, 2008).

The TIS was measured with three items. In terms of the mean and standard deviation, Table 1 shows that the total mean average score was $(\mathrm{M}=1.98 ; \mathrm{SD}=1.44)$ which indicated a lower turnover intention score. The turnover intention skewness was (1.44) and kurtosis (1.04), thereby not falling within -1 and +1 normality range recommended for these coefficients (Howell, 2008).

\section{Correlational statistics}

As illustrated in Table 2, links, fit and sacrifice to organisation correlated significantly and positively with the work engagement sub-dimensions. The correlations varied from $r=0.39$ to 0.48 ( $p \leq 0.000$; medium practical effect size). Links to organisation had a significant correlation of medium practical effect size $(r \geq 0.30 \leq 0.49)$ with vigour $(r=0.48$; $p \leq 0.000)$, dedication $(r=0.48 ; p \leq 0.000)$ and absorption $(r=0.41 ; p \leq 0.000)$. Fit to organisation had a significant correlation of medium practical effect size $(r \geq 0.30 \leq 0.49)$ with vigour $(r=0.47 ; p \leq 0.000)$, dedication $(r=0.47 ; p \leq 0.000)$ and absorption $(r=0.41 ; p \leq 0.000)$. Sacrifice to organisation had a significant correlation of medium practical effect size $(r \geq 0.30 \leq 0.49)$ with vigour $(r=0.46 ; p \leq 0.000)$, dedication $(r=0.45 ; p \leq 0.000)$ and a moderate significant correlation with absorption $(r=0.39 ; p \leq 0.000)$.

As illustrated in Table 2, links, fit and sacrifice to organisation correlated significantly and negatively with turnover intention. The correlations varied from $r=-0.30(p \leq 0.000$; medium practical effect size) to $r=-0.50(p \leq 0.000$; large practical effect size). The strongest negative significant correlation $(r=-0.50 ; p \leq 0.000)$ was observed between links to organisation $(r=-0.50 ; p \leq 0.000)$ and turnover intention. Fit to organisation had a negative significant correlation of medium practical effect size $(r \geq 0.30 \leq 0.49)$, whilst turnover intention $(r=-0.30 ; p \leq 0.000)$ and sacrifice to organisation had a negative correlation with turnover intention $(r=-0.42$; $p \leq 0.000$; medium practical effect).
TABLE 2: Pearson's product-moment correlations: Job Embeddedness Scale, Utrecht Work Engagement Scale and Turnover Intention Scale.

\begin{tabular}{llll}
\hline $\begin{array}{l}\text { Measuring instrument } \\
\text { subscales }\end{array}$ & (JES) Links & Fit & Sacrifice \\
\hline UWES & & & \\
Vigour & $0.48^{*++}$ & $0.47^{*++}$ & $0.46^{*++}$ \\
Dedication & $0.48^{*++}$ & $0.47_{++}$ & $0.45_{++}$ \\
Absorption & $0.41^{*+}$ & $0.41_{++}^{+}$ & $0.3 *_{++}$ \\
TIS & $-0.50^{*+}$ & $-0.30^{*++}$ & $-0.42_{++}$ \\
\hline
\end{tabular}

Note: $n=153$.

JES, Job Embeddedness Scale; UWES, Utrecht Work Engagement Scale; TIS, Turnover Intention Scale.

$*, p \leq 0.001$ (two-tailed);,$+ r \geq 0.50$ (large practical effect size);,$++ r \geq 0.30 \leq 0.49$ (medium practical effect size).

TABLE 3: Pearson's product-moment correlation: Utrecht Work Engagement Scale and Turnover Intention.

\begin{tabular}{lcll}
\hline UWES & Vigour & Dedication & Absorption \\
Turnover intention & $-0.29^{*++}$ & $-0.37^{*+}$ & $-0.25^{* *+}$ \\
\hline Note: $n=153$. & & \\
UWES, Utrecht Work Engagement Scale. & \\
$*, p \leq 0.001 ; * *, p \leq 0.01$ (two-tailed),,$+ r \leq 0.26$ (small practical effect size);,$++ r \geq 0.30 \leq$ \\
0.49 (medium practical effect size).
\end{tabular}

As illustrated in Table 3, vigour, dedication and absorption correlated significantly and negatively with turnover intention. The correlations varied from $(r=-0.25$; small practical effect size, $p \leq 0.002)$ to $(r=-0.37$; medium practical effect size, $p \leq 0.000)$. The strongest significant correlation $(r=-0.37 ; p \leq 0.000 ;$ medium practical effect) was observed between dedication and turnover intention. Vigour had a negative significant correlation of small practical effect size with turnover intention $(r=-0.29 ; p \leq 0.000)$, whereas absorption had a negative significant correlation $(r=-0.25$; small practical effect; $p \leq 0.002$ ) with turnover intention.

In Table 4 significant relationships were observed between total job embeddedness, work engagement and turnover intention $(p \leq 0.000)$. A significant positive relationship $(r=0.51$; large practical effect, $p \leq 0.000)$ was observed between total job embeddedness and work engagement. A statistically significant negative relationship was observed between job embeddedness and turnover intention $(r=-0.42$; medium practical size, $p \leq 0.000)$. Finally, a moderate negative statistically significant relationship was observed between total work engagement $(r=-0.32$; medium practical effect size, $p \leq 0.000$ ) and turnover intention.

The results provided sufficient evidence to support research hypothesis $\mathrm{H}_{\mathrm{a}}$ : a statistically significant relationship exists 
between individuals' job embeddedness, work engagement and turnover intention.

\section{Multiple regression}

Table 5 indicates that the regression models explained $\left(R^{2} \geq 0.13 \leq 0.25\right)$ medium practical effect percentages of variance in the dependent variable (Cohen, 1992).

In terms of the JES variables, regression model 1 in Table 5 shows that the JES variables explain $19 \%\left(R^{2}=0.19\right.$; medium practical effect) of the variance in total turnover intention. Only links to organisation $(\leq=-0.48 ; p=0.06)$ contributed significantly and negatively in explaining the variance in total turnover intention.

In terms of the UWES variables, regression model 2 in Table 5 shows that the UWES variables explain $13 \%\left(R^{2}=0.13\right.$; medium practical effect) of the variance in total turnover intention. Only dedication $(\leq=-0.55 ; p=0.001)$ contributed significantly and negatively in explaining the variance in total turnover intention.

The results provided sufficient evidence to support research hypothesis $\mathrm{H} 2$ : job embeddedness and work engagement significantly and negatively predict turnover intention.

\section{Discussion}

The study explored the relationship between job embeddedness, work engagement and turnover intention. Overall, the results indicated a significant relationship between the participants' job embeddedness and work engagement. The results showed that the participants who had high levels of job embeddedness and work engagement had significantly lower turnover intentions. It appears from the results that employees who feel highly embedded in their jobs experience the need to stay in the organisation. Consistent with the findings of Halbesleben and Wheeler (2008) and Mitchell et al., (2001b), the present results suggest that strong formal or informal connections between an employee and institution or other people, the person's fit with the job and organisation and the perceived personal losses (like giving up colleagues or interesting research projects) may result in keeping the employee in the institution. Similarly, those participants who are highly engaged in their jobs appear to have less intent to leave the institution. These results support the findings of Saks (2006) and Schaufeli and Bakker (2004), namely that engaged employees are likely to have a greater attachment to their organisation and have positive experiences, which leads to a lower propensity to leave the organisation.

The results suggest that job embeddedness is a stronger negative predictor of the participants' turnover intention than work engagement. The findings are in agreement with those of Halbesleben and Wheeler (2008) who found job embeddedness to be a stronger negative predictor of turnover intention as compared to work engagement. In addition, the results suggest that the participants' links were significantly negatively related to their turnover intention. Mitchell et al. (2001b) found that the more the number of links between the person and job or organisation the more he or she feels bound to the job and organisation. In relation to work engagement, the present results also showed that the participants' dedication significantly contributed to lower turnover intention. A study conducted by Barkhuizen and Rothmann (2006) amongst academics supports these findings as they also reported relatively high levels of dedication amongst participants.

Overall, it can be concluded that high levels of job embeddedness (organisational links) and work engagement (dedication) lead to lower turnover intentions. The findings of this study contribute valuable new knowledge on the relationships between these variables, and they focus

TABLE 4: Pearson's product moment correlation: Job Embeddedness Scale, Utrecht Work Engagement Scale and Turnover Intention.

\begin{tabular}{llll}
\hline JES $(N=153)$ & Total job embeddedness & Total work engagement & Turnover intention \\
\hline Total job embeddedness & - & $0.51^{*}+$ & $-0.42^{*}++$ \\
Total work engagement & $0.51^{*}$ & - & $-0.32^{*++}$ \\
Turnover intention & $-0.42^{*++}$ & $-0.32^{*++}$ & - \\
\hline
\end{tabular}

Note: $n=153$.

JES, Job Embeddedness Scale.

${ }^{*}, p \leq 0.001$ (two-tailed);,$+ r \geq 0.50$ (large practical effect size); $++, r \geq 0.30, \leq 0.49$ (medium practical effect size).

TABLE 5: Multiple regression analyses: Job Embeddedness Scale and Utrecht Work Engagement Scale versus Turnover Intention.

\begin{tabular}{|c|c|c|c|c|c|c|c|c|}
\hline \multirow[t]{2}{*}{ Variable } & \multicolumn{2}{|c|}{ Unstandardised coefficient } & \multirow{2}{*}{$\begin{array}{c}\text { Standardised coefficient } \\
\beta \boldsymbol{\beta}\end{array}$} & \multirow[t]{2}{*}{$\bar{t}$} & \multirow[t]{2}{*}{$p$} & \multirow[t]{2}{*}{$F$} & \multirow[t]{2}{*}{ Adjusted } & \multirow[t]{2}{*}{$R$} \\
\hline & $b$ & $S E$ & & & & & & \\
\hline Model 1: JES (Constant) & 5.01 & 0.69 & - & 7.23 & 0.000 & $12.39 * * *$ & $0.19++$ & 0.45 \\
\hline Organisational links & -0.76 & 0.40 & -0.48 & -1.90 & $0.06^{*}$ & - & - & - \\
\hline Fit to organisation & -0.02 & 0.19 & -0.01 & -0.10 & 0.92 & - & - & - \\
\hline Sacrifice to organisation & 0.07 & 0.37 & 0.04 & 0.18 & 0.86 & - & - & - \\
\hline Model 2: UWES (Constant) & 4.35 & 0.56 & - & 7.71 & 0.000 & $8.70^{* * *}$ & $0.13++$ & 0.39 \\
\hline Vigour & 0.02 & 0.30 & 0.01 & 0.07 & 0.95 & - & - & - \\
\hline Dedication & -0.83 & 0.25 & -0.55 & -3.37 & $0.001 * * *$ & - & - & - \\
\hline Absorption & 0.30 & 0.24 & 0.20 & 1.22 & 0.23 & - & - & - \\
\hline
\end{tabular}

Note: $n=153$.

UWES, Utrecht Work Engagement Scale; JES, Job Embeddedness Scale.

${ }^{*}, p \leq 0.10 ;{ }^{* *}, p \leq 0.05 ;{ }^{* * *}, p \leq 0.01 ;{ }^{* * *}, p \leq 0.001 ;+, R^{2} \leq 0.12$ (small practical effect size) $;++, R^{2} \geq 0.13, \leq 0.25$ (medium practical effect size). 
attention on the practical implications of job embeddedness and work engagement in the retention of employees in the higher education context.

\section{Conclusion}

\section{Implications for human resource management}

The findings confirm the need to consider job embeddedness and work engagement in the higher education context in order to understand employees' turnover intention. In view of the argument that embedded and engaged employees demonstrate increased performance and lower intentions of leaving the organisation (Halbesleben \& Wheeler, 2008), it is suggested that the participating higher education institution and its management consider programmes for improving the embeddedness and engagement of its staff in order to reduce turnover intention. In this context, it is suggested that to help employees fit their jobs and the organisation better, as well as enabling them to build stronger links with colleagues, supervisor support is provided that gives guidelines, assistance, trust in and praise for subordinates (Bergiel, Nguyen, Clenney \& Taylor, 2009). Employees are then likely to become more embedded in their jobs and less likely to leave their organisation (Mitchell et al., 2001a). The results showed that engaged and dedicated employees have lower turnover intention, so the higher education environment should be encouraged to help sustain employees' vigour and dedication by providing, for example, meaningful work activities, flexible working arrangements, opportunities for growth and development and incentive compensation (Saks, 2006; Van den Berg et al., 2008).

The higher education institution in this study should explore the extent to which provision is made for personal and professional development. Embeddedness and engagement can be promoted through training programmes that target both organisational health and individual well-being so that a positive emotional climate is created in the workplace (Schaufeli \& Salanova, 2008). Growth opportunities imply that employees have the chance to develop and demonstrate their potential, which may lead them to better fit their jobs and the organisation. Employees may thus be more embedded in their jobs and less likely to leave when there are opportunities for personal and professional development (Bergiel et al., 2009). Management could enhance engagement by coaching employees on setting goals, developing career plans, and by pointing out pitfalls and giving advice where necessary (Barkhuizen \& Rothmann, 2006). In addition, job resources with a positive impact, such as feedback from the supervisor, collegial support, social contact and personal growth may result in higher levels of vigour and dedication amongst employees (Van den Berg et al., 2008).

Mitchell et al. (2001a) suggest non-financial incentives such as sabbatical leave or flexible work schedules to enhance employee embeddedness. Socialisation tactics, network groups, mentoring to address early career needs for guidance, support, affirmation and developing a sense of belonging could actively embed newcomers in the organisation in an effort to reduce turnover intention (Allen, 2006; Freidman \& Holtom, 2002).

\section{Limitations and recommendations for future research}

This study used self-report questionnaires to gather data on all three measures at one point in time. The cross-sectional research design limits the possibility of drawing conclusions about the causal nature of the relationships and gives no idea of change in behaviour and perceptions over time. Hence it is recommended that future research uses a longitudinal design to examine the impact of job embeddedness and work engagement on employees' turnover intention. Because this study was exploratory in nature and involved only a small non-probability purposive sample of participants, generalising the findings to the larger context of the higher education institution concerned, and to other occupational contexts cannot be done. However, the significant associations found between the variables of relevance to the study warrant future research with larger samples in other higher education institutions. Such studies could also consider comparing the results with other population groups in industry.

Despite these limitations, the results of this study provide valuable new insights regarding the relationship between job embeddedness, work engagement and turnover intention as they apply to the South African higher education context. The research also provides a platform for future studies using larger samples from within this sphere.

\section{Acknowledgements Competing interests}

The authors declare that they have no financial or personal relationship(s) which may have inappropriately influenced them in writing this article.

\section{Authors' contributions}

N.T. (University of South Africa) conducted the literature review and statistical analyses and wrote up the article. M.C. (University of South Africa) acted as co-supervisor of the research project, assisted with the statistical analyses and reviewed the article. D.S. (University of South Africa) acted as supervisor of the research project and assisted with the review of the article.

\section{References}

Albrecht, S.L. (2013). Work engagement and the positive power of meaningful work Advances in Positive Organisational Psychology, 1, 237-260. http://dx.doi. org/10.1108/S2046-410X(2013)0000001013

Allen, D.G. (2006). Do organisational socialisation tactics influence newcomer embeddedness and turnover? Journal of Management, 32(2), 237-256. http:// dx.doi.org/10.1177/0149206305280103

Al-Sharafi, H., \& Rajiani, I. (2013). Leadership practices and talent turnover: Study on Yemeni organisations. Business and Management Research, 2(3), 60-67. http:// dx.doi.org/10.5430/bmr.v2n3p60

Bakker, A.B., \& Demerouti, E. (2008).Towards a model of work engagement Career Development International, 13(3), 209-223. http://dx.doi. org/10.1108/13620430810870476 
Bakker, A.B., Schaufeli, W.B., Leiter, M.P., \& Taris, T.W. (2008). Work engagement: An emerging concept in occupational health. Work and Stress, 22, 187-200. http:// emerging concept in occupational health
dx.doi.org/10.1080/02678370802393649

Barkhuizen, N.,\& Rothmann, S. (2006). Work engagement of academic staff in South African higher education institutions. Management Dynamics, 15(1), 38-46.

Bergiel, B.E., Nguyen, V.Q., Clenney, B.F., \& Taylor, G.S. (2009). Human resource practices, job embeddedness and intention to quit. Management Research News, 32(3), 205-219. http://dx.doi.org/10.1108/01409170910943084

Bothma, C.F.C., \& Roodt, G. (2013). The validation of the turnover intention scale. SA Journal of Human Resource Management, 11(1), 507-519. http://dx.doi. org/10.4102/sajhrm.v11i1.507

Burke, R.J., \& El-Kot, G. (2010). Work engagement among managers and professionals in Egypt: Potential antecedents and consequences. African Journal of Economics and Management Studies, 1(1), 42-60. http://dx.doi.org/10.1108/20400701011028158

Burton, J.P., Holtom, B.C., Sablynski, C.J., Mitchell, T.R., \& Lee, T.W. (2010). The buffering effects of job embeddedness on negative shocks. Journal of Vocational Behavior, 76, 42-51. http://dx.doi.org/10.1016/j.jvb.2009.06.006

Coetzee, M., \& Rothman, S. (2004). An adapted model of burnout for employers at a higher education institution in South Africa. South African Journal of Industria Psychology, 30(3), 29-40.

Coetzee, M., \& Schreuder, D. (2010). Personnel psychology: An applied perspective. Cape Town: Oxford University Press.

Cohen, J. (1992). Quantitative methods in psychology: A power primer. Psychological Bulletin, 112(1), 153-159. http://dx.doi.org/10.1037/0033-2909.112.1.155

Cropanzano R.S., \& Wright, T.A. (2001). When a 'happy'worker is really a 'productive'worker: A review and further refinements of the happy-productive worker thesis. Consulting Psychology Journal 53(3), 182-199. http://dx.doi. org/10.1037/1061-4087.53.3.182

Crossley, C.D., Bennet, R.J., Jex, S.M., \& Burnfield, J.L. (2007). Development of a global measure of job embeddedness and integration into a traditional model of voluntary turnover. Journal of Applied Psychology, 92(4), 1031-1042. http://dx.doi. org/10.1037/0021-9010.92.4.1031

Du Plooy, J., \& Roodt, G. (2010). Work engagement, burnout and related constructs as predictors of turnover intention. South African Journal of Industrial Psychology, 36(1), 1-13.

Frank, F.D., Finnegan, R.P., \& Taylor, C.R. (2004). The race for talent: Retaining and engaging workers in the 21st century. Human Resource Planning, 27(3), 12-24.

Friedman, R.A., \& Holtom, B. (2002). The effect of network groups on minority employee turnover intentions. Human Resource Management, 41(4), 405-421. http://dx.doi. org/10.1002/hrm.10051

Halawi, A.L., Aronson, E.L., \& McCarthy, V.R. (2005). Resource-based view of knowledge management for competitive advantage. The Electronic Journal of Knowledge Management, 3(2), 75-86

Halbesleben, R.B. (2010). A meta-analysis of work engagement: Relationship with burnout, demands, resources and consequences. In A. B. Bakker (Ed), \& M. P. Leiter. Work engagement: A handbook of essential theory and research (pp.102-117) New York: Psychology Press.

Halbesleben, J.R.B., \& Wheeler, A.R. (2008). The relative roles of engagement and embeddedness in predicting job performance and intentions to leave. Work \& Stress, 22(3), 242-256. http://dx.doi.org/10.1080/02678370802383962

Harter, J.K., Schmidt, F.L., \& Hayes, T.L. (2002). Business-unit level relationship between employee satisfaction, employee engagement, and business outcomes: A meta-analysis. Journal of Applied Psychology, 87(2), 268-279. http://dx.doi. org/10.1037/0021-9010.87.2.268

Hillmer, S., Hillmer, B., \& McRoberts, G. (2004). The real costs of turnover: Lessons from a call center. Human Resource Planning, 27(3), 34-41.

Holtom, B.C., Mitchell, T.R., \& Lee, T.W. (2006).Increasing human and social capital by applying job embeddedness theory. Organisational Dynamics, 35(4), 316-331. $\mathrm{http}: / / \mathrm{dx}$.doi.org/10.1016/j.orgdyn.2006.08.007

Howell, D.C (2008). Fundamental statistics for the behavioural sciences $\left(6^{\text {th }}\right.$ ed.). Belmont, CA: Thomson Wadsworth.

Karatepe, O.M., \& Ngeche, R.N. (2012). Does job embeddedness mediate the effect of work engagement? A study of hotel employees in Cameroon. Journal of Hospitality Marketing and Management, 21(94), 440-461. http://dx.doi.org/10.1080/193686 23.2012.626730

Kidwell, J.J., Vander Linde, K.M., \& Johnson, L.S. (2000). Applying corporate knowledge management practices in higher education. Educause Quarterly, 23(4), 28-33.

Lawler, E.E. (2008). Talent: Making people your competitive advantage. San Francisco, CA: Jossey-Bass.

Lawler, E.E., \& Finegold, D. (2000). Individualising the organisation: Past, present and future. Organisational Dynamics, 29(1), 1-15. http://dx.doi.org/10.1016/S0090future. Organisationd
2616(00)00009-7

Lee, T.W., Mitchell, T.R., Sablynski, C.J., Burton, J.P., \& Holtom, B.C. (2004). The effects of job embeddedness on organizational citizenship, job performance, volitional absences, and voluntary turnover. Academy of Management Journal, 47, 711-722. absences, and voluntary turnover. Acade
http://dx.doi.org/10.2307/20159613

Leedy, P.D., \& Ormrod, J.E. (2005). Practical research: Planning and design. (8th ed.). Upper Saddle River, NJ: Prentice-Hall.
Macey, W.H., \& Schneider, B. (2008).The meaning of employee engagement. Industrial and Organisational Psychology, 1(1), 3-30. http://dx.doi.org/10.1111/j.17549434.2007.0002.x

Makhanya, M. (2012). Student graduateness. In M. Coetzee, J. Botha, N. Eccles, N. Holtzhauzen \& H. Nienaber (Eds), Developing student graduateness and employability, (p. 29). Randburg: Knowres.

Marchington, M., \& Wilkinson A.(2008). Human resource management at work: People management anddevelopment (4th ed.).London: Chartered Institute of Personnel and Development.

Martin, A., \& Roodt, G. (2008). Perceptions of organisational commitment, job satisfaction and turnover intentions in a post-merger South African tertiary institution. SA Journal of Industrial Psychology, 34 (1), 23-31.

Maslach, C., Schaufeli, W.B., \& Leiter, M.P. (2001). Job burnout. Annual Review of Psychology, 52, 397-422. http://dx.doi.org/10.1146/annurev.psych.52.1.397

Mauno, S., Kinnunen, U., \& Ruokolainen, M. (2006). Job demands and resources as antecedents of work engagement: A longitudinal study. Journal of Vocational Behaviour, 70, 149-171.

Michaels, E.D., Handfield-Jones, H., \& Axelrod, B. (2001). The war for talent. Cambridge, MA: Harvard Business Press.

Mitchell, T.R., Holtom, B.C., \& Lee, T.W. (2001a). How to keep your best employees: Developing an effective retention policy. Academy of Management Executive, 15(4), 96-109.

Mitchell, T.R., Holtom, B.C., Lee, T.W., Sablynski, C.J., \& Erez, M. (2001b). Why people stay: Using job embeddedness to predict voluntary turnover. Academy of Management Journal, 44(6), 1102-1121.

Mitchell, T.R., \& Lee, T.W. (2001). The unfolding model of voluntary turnover and job embeddedness: Foundations for a comprehensive theory of attachment. Research in Organisational Behaviour, 23, 189-246. http://dx.doi.org/10.1016/S01913085(01)23006-8

Morrell, K., Loan-Clarke, J. \& Wilkinson, A. (2004). The role of shocks in employee turnover. British Journal of Management, 15, 335-349. http://dx.doi.org/10.1111/j.14678551.2004.00423.x

Netswera, F.G., Rankumise, E.M., \& Mavundla, T.R. (2006). Employee retention factors for South African Higher Education Institutions: A case study. South African Journal of Human Resource management, 3(2), 36-40.

Ngobeni, E.K., \& Bezuidenhout, A. (2011). Engaging employees for improved retention at a higher education institution in South Africa. African Journal of Business Management 5(23), 9961-9970.

Pfeffer, J. (2005). Producing sustainable competitive advantage through the effective management of people. Academy of Management Executive, 19(4), 95-106. http:// dx.doi.org/10.5465/AME.2005.19417910

Powell, W.W., \& Snellman, K. (2004). The knowledge economy. Annual Review of Sociology, 30, 199-220. http://dx.doi.org/10.1146/annurev.soc.29.010202.100037

Price, J. (2001). Reflections on the determinants of voluntary turnover. Internationa Journal of Manpower, 22, 600-624. http://dx.doi.org/10.1108/EUM0000000006233

Probst, G., Raub, S., \& Romhardt, K. (2000) Managing knowledge: Building blocks for success. London: Wiley.

Ryder, A. (2010). NGOs and salary allocation: The new reality for South African NGOs, 2010. Retrieved March 01, 2011 from www.ngopulse.org/article/ngos-and-salaryallocations.

Saks, A.M. (2006). Antecedents and consequences of employee engagement. Journal of Managerial Psychology, 21(7), 600-619. http://dx.doi. org/10.1108/02683940610690169

Schaufeli, W.B., \& Bakker, A.B. (2003). Utrecht Work Engagement Scale. Preliminarymanual. Utrecht: Utrecht University.

Schaufeli, W.B., \& Bakker, A.B. (2004). Job demands, job resources, and their relationship with burnout and engagement: A multi-sample study. Journal of Organisational Behavior, 25, 293-315. http://dx.doi.org/10.1002/job.248

Schaufeli, W.B., \& Salanova, M. (2008). Enhancing work engagement through the management of human resources. In Naswall, K., Sverke, M \& Hellgren, J. (Eds.). The individual in the changing working life (pp. 380-402). Cambridge, MA: Cambridge University Press.

Schaufeli, W.B., Salanova, M., Gonzalez-Roma, V., \& Bakker, A.B. (2002). The measurement of engagement and burnout: A confirmative analytic approach. Journal of Happiness Studies, 3, 71-92. http://dx.doi.org/10.1023/A:1015630930326

Shikha, V.G. (2012). Talent acquisition and retention issues of faculty in higher education. Journal of Human Resource Management and Development, 2(2), 20-31.

Shimazu, A., Schaufeli, W.B., Kubota, K., \& Kawakami, N. (2012). Do workaholism and work engagement predict employee well-being and performance in opposite directions? Industrial Health, 50, 316-321.

Smyth, R., Zhai, Q., \& Li, X. (2009). Determinants of turnover intentions among Chinese off farm migrants. Econ Change Restruct, 42, 189-209. http://dx.doi.org/10.1007/ s10644-008-9067-z

Sousa-Poza, A., \& Henneberger, F. (2002). Analyzing job mobility with job turnover intentions: An international comparative study. Research Institute for Labour Economics and Labour Law, 82, 1-28.

SPSS for Windows, Rel. 20.0.0. (2011). Chicago: SPSS Inc. 
Storm, K., \& Rothmann, S. (2003). A psychometric analysis of the Utrecht Work Engagement Scale in the South African Police Service. South African Journal of Engagement Scale in the South African Police Service. South African Journal
Industrial Psychology, 29, 62-70. http://dx.doi.org/10.1177/008124630303300404

Tredoux, C., \& Durrheim, K. (2013). Numbers, hypotheses and conclusions. (2nd Ed). Cape Town: UCT Press.

Van den Berg, H., Manias, D., \& Burger, S. (2008). The influence of job-related factors on work engagement of staff at University of the Free State. Acta Academica, 4O(3), 85-114.

Van den Berg, B.A.M., Bakker, A.B., \& Ten Cate, T.J. (2013). Key factors in work engagement and job motivation of teaching faculty at a university medical centre. Perspectives on Medical Education. 2(5-6): 264-275. http://dx.doi.org/10.1007/ s40037-013-0080-1
Xanthopoulou, D., Bakker, A.B., Demerouti, E., \& Schaufeli, W.B. (2007). The role of personal resources in the job demands-resources model. International Journal of Stress Management, 14, 121-141. http://dx.doi.org/10.1037/10725245.14.2.121

Yao, X., Lee, T.W., Mitchell, T.R., Burton, J.P., \& Sablynski, C.S. (2004). Job embeddedness: Current research and future directions. In R. Griffeth \& P. Hom embeddedness: Current research and future directions. In R. Griffeth \& P. Hom
(Eds.), Understanding employee retention and turnover (pp.153-187). Greenwich, CT: Information Age.

Yeh, C.M. (2013). Tourism involvement, work engagement and job satisfaction among frontline hotel employees. Annals of Tourism Research, 42, 214-239. http:// dx.doi.org/10.1016/j.annals.2013.02.002 